\title{
Workplace Injury Risk Prediction and Risk Reduction Tools for Electronics Assembly Work
}

\author{
A Software Tool for the Non-Ergonomist
}

\author{
Leonard O'Sullivan and Timothy Gallwey \\ Manufacturing and Operations Engineering Department, University of Limerick, \\ Plassey Technological Park, Limerick, Ireland. \\ Email: \{leonard.osullivan,timothy.gallwey\}@ul.ie
}

\begin{abstract}
Ergonomics approaches to risk of musculo skeletal disorders are often reactive rather than proactive, an approach supported by a lack of ergonomics expertise, especially in small to medium size companies. However, the EU framework directive on health and safety at work (89/391/EEC) demands a comprehensive risk assessment by the employer. Further, the machinery directive (89/392/EEC), demands a comprehensive risk assessment at an early design stage. Presented are the results of field studies that have identified suitable risk evaluation methods for electronics assembly and rework tasks. To assist nonexpert ergonomists, a risk reduction module is also presented. Combined, the risk evaluation and risk reduction approachs presented here provide a framework for reducing musculsoskeletal disorders in line with EU safety directives.
\end{abstract}

Key words: Musculoskeletal disorders, Interventions, Risk, Assessment.

\section{INTRODUCTION}

Work-related Musculo-Skeletal Disorders (WMSDs) are common in the majority of industrial settings. Clinical and epidemiological studies have identified four main factors that help identify high risk tasks, i.e. inadequate postures, repetitiveness, high levels of force, and lack of rest. A lot of industries, for example computer and other high tech industries, involve considerable amounts of assembly work, which by nature is very difficult to automate. For assembly type tasks, a lot of concern focuses on Repetitive Strain 
Injuries (RSIs) of the wrist. Although these tasks may be hand intensive, injuries are not isolated to the hand and wrist as arm movement requires continuous activation of the shoulder girdle and the glenohumeral joint (WINKEL, WESTGAARD 1992). GRIECO (1998) in addition to wrist injuries described incidences of shoulder tendinitis, lateral epicondylitis, and tension neck syndrome for repetitive tasks. In a study of an aircraft engine plant, DIMBERG (1987) found that $7.4 \%$ of workers had lateral epicondylitis.

However, many small and medium size enterprises (SMEs) often cannot afford the services of ergonomics specialists to evaluate workplace risks and make design improvements. This is supported by a review of the practical implementation of EU safety directives (Trade Union Technical Bureau, 2004) that found costs to be an impediment for SMEs. But, new EU directives on workplace ergonomics necessitate the need for safe workplace design such that the risk of injury to employees are minimised. However, the benefits of successful ergonomics interventions are not limited to reduced injury claims, as better workplace layout also improves productivity and product manufacture quality. Therefore the benefits of good ergonomics layout can be of immense benefit to SMEs.

Various workplace evaluation techniques are available that range in application complexity and risk sensitivity. The majority of these are performed by observation and the result is an overall risk rating for a task, often in the form of action levels. The risk ratings are based on task data relating to limb joint angles, repetition, force of exertion and recovery time. Evaluation techniques provide risk ratings for tasks but the results do not indicate the risk rating for each body part. Furthermore, the techniques do not provide the user with suggestions on task redesign for the reduction of risk ratings.

As part of the development of a computerised workplace evaluation suite of tools for an EU funded project, work was undertaken to enhance existing ergonomics evaluation techniques such that non-ergonomists could perform simple risk assessments and follow guidelines on task redesign to reduce the risk of injury associated with tasks. In this respect it is important that guidelines are provided to these users to also help them reduce high-risk levels through administrative and engineering interventions. In the following a risk reduction approach is shown which incorporates a suite of evaluation tools. The current draft is a suggested framework for reducing risk levels in the redesign of work and is a compilation of approaches from various sources within the ergonomics literature. 


\section{RISK ASSESSMENT}

\subsection{Need to Include Risk Reduction}

In many cases, job analysis can be accomplished by observation and discussing with employees the tasks they are performing. An adequate analysis should identify all risk factors present in each task studied. Figure 1 presents a definition of risk analysis and risk assessment according to EN 1050. However, many SMEs that do contract electronic assembly and rework contracts often do not have access to expert ergonomics judgment. Simple ergonomic evaluation methods that are easy to learn can highlight problematic tasks, but difficulty arises in the risk reduction phase during interventions as the skills required to redesign tasks safety are by its nature a form of tacit knowledge.

The approach in this work was to (a) provide risk analysis tools for electronics industry, and (b) provide a risk reduction approach that is integrated with the risk evaluation stage of a complete assessment.

\subsection{Selection of Risk Evaluation Methods}

Field studies were performed using various risk assessment methods in electronics industries. Based on the results, four methods were chosen for use by either expert ergonomists or non-experts. Production managers and health and safety personnel were regarded as potential non-expert users in SME electronics companies. These methods were programmed using Visual Basic software for ease of use. The application provides for quick evaluation of workplaces from digital photographs or video recordings.

The final tool set includes RULA (MCATAMNEY, CORLETT 1993), REBA (HIGNETT, McATAMENY 2000), the Strain Index (MOORE, GARG 1995) and OCRA (OCCHIPINTI 1998). RULA and REBA are similar since $R E B A$ is just an extension of the RULA approach to the rest of the body, instead of being confined to the upper limbs. However, because it was developed later and has achieved less publicity, REBA is less well known and so is likely to be used only when newcomers have become accustomed to $R U L A$. Also, it was felt that those who were familiar with $R U L A$ (in many cases the only tool they know) would be upset if it was missing and would therefore be discouraged from using the final version. On this basis both were incorporated. The Strain Index is probably even less widely known but it has some attractive features in that it takes into account some measures not included in other tools. The fact that it results in an index number is also an attractive feature although the base of case material used to set the bands of acceptability etc. was rather small for some. 


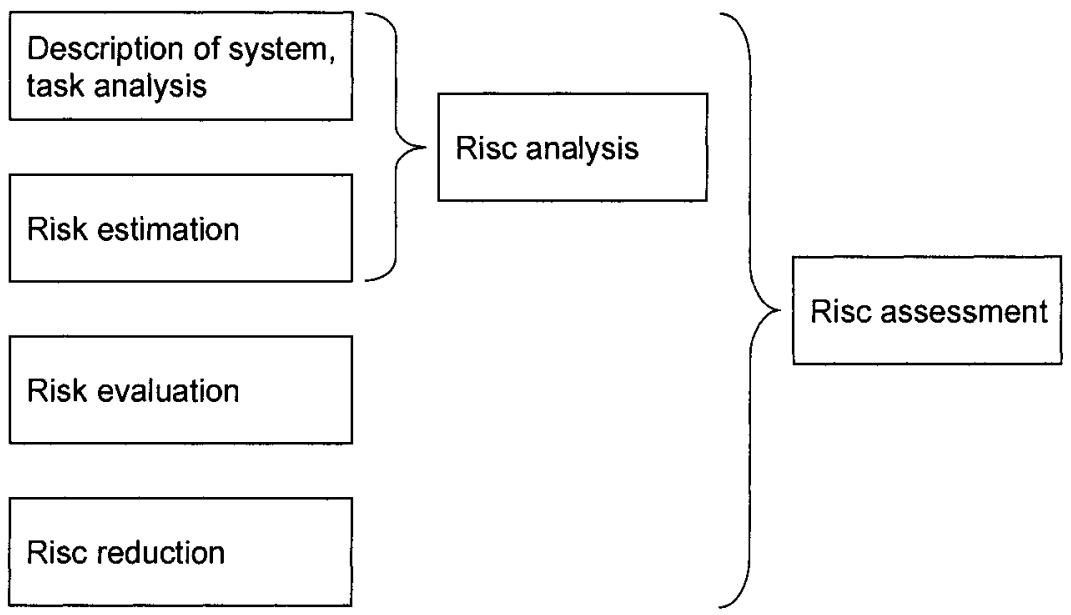

Figure 1, Definition of risk analysis and risk assessment according to EN 1050

Table 1 shows the decision matrix for selection of methods. It is based on level of assessment detail required and the level of ergonomics expertise of the user.

Table 1 . Risk assessment methods

\section{Ergonomics expertise}

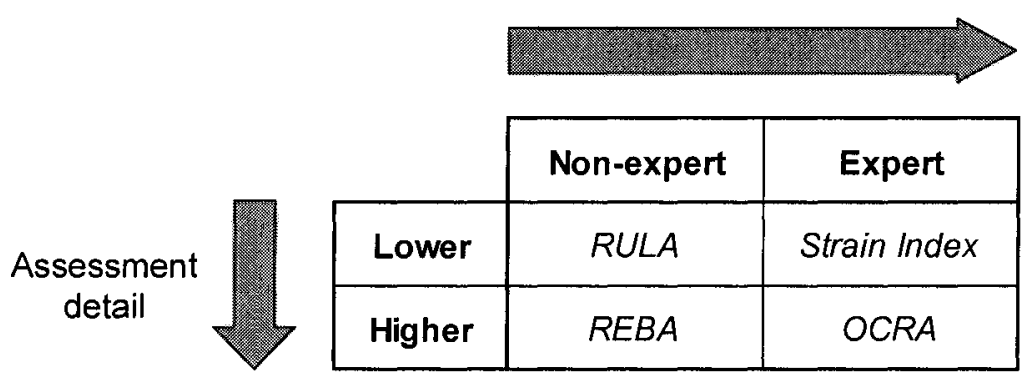

\subsection{Field Studies}

An expert ergonomist evaluated thirty electronics assembly and reworking tasks using each of the evaluation methods. Sample tasks are show in Figure 2 and Figure 3. A correlation analysis (Spearman's rho coefficient) was performed on the results. The data (Table 2) show a pattern of two groups of significant correlations $(\mathrm{p}<0.05)$. 


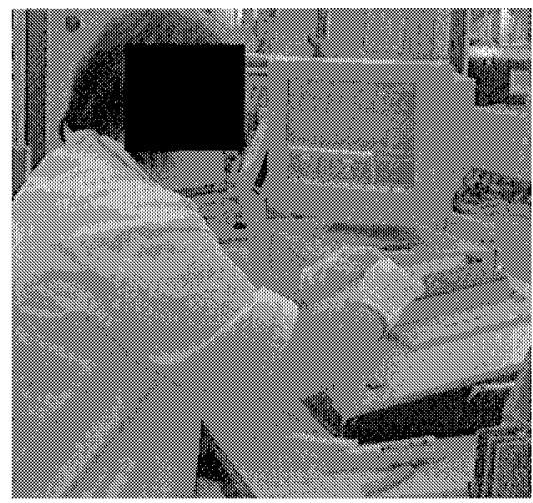

Figure 2. Assembly task

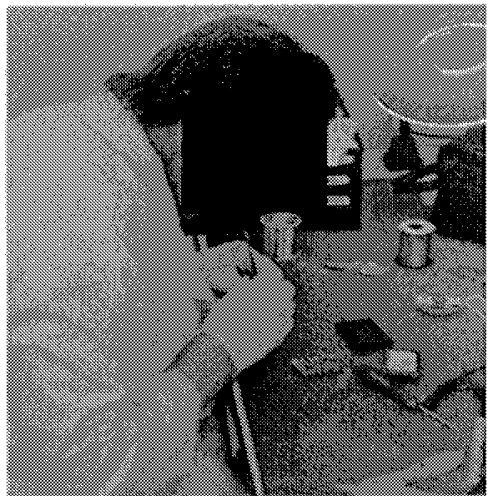

Figure 3. Circuit reworking

The first set is between the RULA and REBA scores and the second between Strain Index and $O C R A$ score. This indicates that there is agreement between RULA and REBA in the estimation of risk for the tasks. But, the grouping of Strain Index and OCRA estimates together suggest that they are (a) both rating the same tasks as high and low risk, and (b) they are both assessing risk factors more thoroughly and estimating different risk estimates than the broad assessments of RULA and REBA. Hence, these data support the selection of the tools for the target users in this type of industry.

\section{RISK REDUCTION}

The risk reduction guidelines were structured in four parts in the order that they are to be used. The approach firstly provides guidance on the initial rectification of the workplace including a framework for making an intervention. General ergonomics guidance from published guidelines are given followed by a more systems approach review of the design of the work. The final stage of the risk reduction approach includes specific points on hardware aids for the worker and issues with static loads.

The technical content of the risk reduction module is also provided as a help file in the Visual Basic software of the risk evaluation tools. Combined, these provide a complete approach of risk analysis, risk evaluation and risk reduction that is convenient to use. These are detailed in the following sections. 
Table 2. Correlation of RULA, REBA, Strain Index and OCRA scores for 30 electronics tasks

\begin{tabular}{|c|c|c|c|c|c|c|c|}
\hline & $\begin{array}{c}R U L A \\
\text { Left hand }\end{array}$ & $\begin{array}{l}\text { RULA } \\
\text { Right } \\
\text { hand }\end{array}$ & $\begin{array}{c}\text { REBA } \\
\text { Left }\end{array}$ & $\begin{array}{l}\text { REBA } \\
\text { Right }\end{array}$ & $\begin{array}{l}\text { Strain } \\
\text { Index }\end{array}$ & $\begin{array}{c}\text { OCRA } \\
\text { Left } \\
\text { hand }\end{array}$ & $\begin{array}{l}\text { OCRA } \\
\text { Right } \\
\text { Hand }\end{array}$ \\
\hline $\begin{array}{c}\text { RULA } \\
\text { Left }\end{array}$ & 1.0 & $0.586\left(^{* *}\right)$ & $0.5811^{* *}$ & -0.016 & 0.194 & 0.351 & 0.205 \\
\hline $\begin{array}{l}\text { RULA } \\
\text { Right }\end{array}$ & & 1.0 & $\left.0.520{ }^{* \star}\right)$ & $0.566\left(^{\star \star}\right)$ & 0.175 & -0.027 & $0.458\left(^{\star}\right)$ \\
\hline $\begin{array}{l}\text { REBA } \\
\text { Left }\end{array}$ & & & 1.0 & $0.569\left(^{* *}\right)$ & 0.293 & 0.129 & 0.071 \\
\hline $\begin{array}{l}\text { REBA } \\
\text { Right }\end{array}$ & & & & 1.0 & 0.218 & -0.185 & 0.221 \\
\hline $\begin{array}{l}\text { Strain } \\
\text { Index }\end{array}$ & & & & & 1.0 & $0.395\left(^{*}\right)$ & $0.441\left(^{*}\right)$ \\
\hline $\begin{array}{c}\text { OCRA } \\
\text { Left }\end{array}$ & & & & & & 1.0 & $0.389\left(^{*}\right)$ \\
\hline $\begin{array}{l}\text { OCRA } \\
\text { Right }\end{array}$ & & & & & & & 1.0 \\
\hline * & $\begin{array}{l}\text {; } \\
\text {;orrelation is }\end{array}$ & $\begin{array}{l}\text { s significa } \\
\text { s significa }\end{array}$ & $\begin{array}{l}n t \text { at } p<0.0 \\
n t \text { at } p<0.0\end{array}$ & $\begin{array}{l}5 \text { level } \\
1 \text { level }\end{array}$ & & & \\
\hline
\end{tabular}

\subsection{Initial Rectification of the Workplace}

In many cases it becomes apparent very quickly that there are a number of fairly simple and obvious changes that need to be made. Before carrying out a detailed analysis and improvement programme as described below, it is suggested to rectify these obvious deficiencies first. Doing so may render detailed study unnecessary. Alternatively, the problem(s) may be eliminated or reduced substantially by changes in the organisation of the work. A variety of suggestions are set out below.

\subsubsection{Consult the Workers}

It is the workers who experience the discomfort and inconvenience involved in doing the job, and these are difficult if not impossible for an observer to detect. The worker can tell the investigator what these are, where the pain/discomfort is felt, and what difficulties are experienced in doing the job. From continued experience of a limited range of activities the worker 
can often also make useful suggestions for improvement of the workplace design.

\subsubsection{Repeat the Observation/Improvement Cycle}

Often, once the first set of improvements has been made, it is found that still more changes are needed. Similarly, one set of initial changes may themselves cause some other, new deficiencies. In either case further investigation is needed, and several cycles of this process might result.

\subsubsection{Consider Job Rotation or Job Sharing}

In some cases it may be very difficult or even impossible to rectify completely some problem aspects. In such cases rotating the job between two or more workers can relieve exposure of the individual. Such a reduction in exposure also reduces the time required for recovery from the pain or discomfort and so productivity will be increased.

\subsubsection{Re-allocate Some of the Tasks}

Rather than have one worker perform several adverse tasks it may be possible to spread these among several workers instead, i.e. spread the pain around. In this way recovery from one or two adverse tasks may take place while performing several other "easy" tasks. KONZ and JOHNSON (2000) have described this as "working rest" which makes the point rather clearly. Another version of this strategy is to allocate one or more of the adverse tasks to a machine or other piece of equipment. Provided the expense is manageable this can be a very effective measure.

\subsubsection{Types of Control}

It is common to classify the controls of risk on two levels, namely technical and administrative controls:

1. Technical controls (engineering controls) will be used to reduce or eliminate the hazards by technical manoeuvres like design of the workplace, design of the tools and working methods, and design of the product.

2. Administrative controls are manoeuvres that effect the organisation of the work or on the ways the work is done. These include, allocating workers to different tasks, working schedules, rotation of workers between different tasks, rules for performing the work, and training of working techniques. 


\subsection{General Ergonomics Measures}

The basic rule is that the job activities, workplace design, and equipment design must be arranged to suit the person doing the job. This means that the worker should perform the tasks that make up the job in ways that are as close as possible to being "natural". All other parts of the work must be changed to fit human capabilities. As a general guide to fulfil these aims CORLETT (1978) enunciated a set of principles.

\subsubsection{Corlett's Principles}

As the list of Corlett's principles is worked through from top to bottom each level incorporates more of the items in the level above, thus becoming more complex and making it increasingly likely that an adequate design decision will be a compromise. At the same time, principles attached to any items are subject to the overriding effect of principles attached to items at a higher level. By this arrangement each decision in designing a work situation should take account, to some extent, of the complexity of people and avoid the sub-optimisation which sometimes arises.

\subsubsection{Typical Disorders and Things to Avoid}

The following is adapted from KROEMER (1989). He notes that most of the typical disorders are easily observable: rapid and frequently repeated actions; exertion of finger or arm forces; contorted body joints; blurred outlines of the body owing to vibration; the feeling of cold and the hissing sound of fast flowing air. Training of operators in physiologically correct activities, and the provision of alternating work (to allow "breaks" in otherwise repetitive or maintained activities) are also essential.

\subsection{Examine the Design of the Work}

Often there are features of the work design that can be changed to reduce the ergonomics deficiencies and thereby reduce or eliminate the postural problems at source. The process requires a highly detailed examination of all elements of the tasks that make up the job. It should be broken down into the set of tasks involved, a task being defined as "the smallest part of the work that can be allocated to a separate operator". This is task analysis.

Task analysis also raises questions as to whether some tasks presently performed by a person should instead be allocated to a machine (including a computer) or the reverse. Changing these allocations offers further opportunities to reduce or eliminate ergonomics problems and/or improve produc- 
tivity. A convenient way to examine these issues is set out by means of a critical questioning matrix as recommended by KONZ and JOHNSON (2000).

\subsection{Specific Workplace Design Recommendations}

\subsubsection{Use Hardware to Assist the Work}

In many manufacturing jobs the designer provides jigs and fixtures to obtain accuracy in machining or assembly. Often, opening and closing them or positioning the work piece, calls for more movements on the part of the operator than are strictly necessary. For example, a tool may have to be used to tighten a nut when a wing nut would be more suitable; or the top of the jig may have to be lifted off to insert a part when the part might be slid into it instead.

\subsubsection{Avoid Static Load}

This maintains a static contraction of a muscle often from a hold or from maintaining a particular posture. The effect is to impede the flow of blood to and from the muscle in question thus starving it of nutrients and creating a build-up of waste products. But when work is dynamic and rhythmic the alternating contracting and relaxing of the muscle assists both processes.

\section{DISCUSSION}

The risk evaluation and reduction approach provides details for a suitable framework for both expert ergonomists and non-experts. This allows for screening of tasks within the company with reduction approaches for initial rectification. If desired, the enterprise can follow up on highrisk/problematic tasks that are difficult to improve by buying in ergonomics expertise. This is a lot more cost effective, especially for SMEs that may not be in a position to buy in expertise for a complete evaluation.

Finalisation of the evaluation methods and risk reduction approach was made in conjunction with testing in industrial reference groups. These will also be used for software testing in conjunction with case study compilation as part of a computer based training (CBT) tool development. The final result of the project will be a software tool for use by a wide cross-section of people employed in the design of products and workplaces. It will be offered on the internet with a CBT program and a CD-ROM with a suite of case study applications to assist users. Due to their ease of use and speed, these 
tools will enable more situations to be analysed, in more detail, more thoroughly, and in less time.

\section{ACKNOWLEDGEMENTS}

The research in this paper was funded by the European Union "Growth" Programme (Musculoskeletal Injuries Reduction Tool for Health and Safety, GIRTH-CT-2001-00574).

\section{REFERENCES}

89/391/EEG:

European Council Directive 89/391 on the introduction of measures to encourage improvements in the safety and health of workers at work.

12. June 1989.

89/392/EEG:

European Council Directive 89/392 on the approximation of the laws of the Member

States relating to machinery.

29. June 1989.

EN 1050:

Safety of machinery. Principles for risk assessment.

1996.

CORLETT, E. N.:

The human body at work: New principles for designing workspaces and methods.

In: Management Services,

Lichfield, 22(1978), pp. 52-53.

HIGNETT S.; MCATAMNEY L,:

Rapid Entire Body Assessment (REBA).

In: Applied Ergonomics,

Amsterdam, 31(2000), pp. 201-205.

KONZ, S.; JOHNSON, S. L.:

Work Design: Industrial Ergonomics.

Scottsdale, AZ: Holcomb Hathaway Publishers, 5th ed. 2000.

KROEMER, K. H. E.:

Cumulative trauma disorders: Their recognition and ergonomics measures to avoid them.

In: Applied Ergonomics,

Amsterdam, 20(1989), pp. 274-280.

KROEMER, K. H. E.; GRANDJEAN, E.:

Fitting the Task to the Human: A Textbook of Occupational Ergonomics.

London: Taylor and Francis, 5th ed. 1997.

MATAMNEY, L; CORLETT, E. N.:

$R U L A$ : A survey method for the investigation of work-related upper limb disorders.

In: Applied Ergonomics, Amsterdam, 24(1993)2, pp 91-99. 
MOORE, J. S., GARG, A.:

The strain index: A proposed method to analyse jobs for risk of distal upper extremity disorders.

In: American Industrial Hygiene Association Journal, Fairfax, 56(1995), pp. 443-458.

OCCHIPINTI, E.:

OCRA: A concise index for the assessment of exposure to repetitive movements of the upper limbs.

In: Ergonomics, London, 41(1998), pp. 1290-1311.

WINKEL, J.; WESTGAARD, R.:

Occupational and individual risk factors for shoulder-neck complaints: Part I - Guidelines for the practitioner.

In: International Journal of Industrial Ergonomics, Amsterdam, 10(1992), pp. 79-83.

GRIECO, A.:

Application of the concise exposure index (OCRA) to tasks involving repetitive movements of the upper limbs in a variety of manufacturing industries: preliminary validation.

In: Ergonomics, London, 41(1998) pp. 1347-1356.

DIMBERG, L.:

The prevalence and causation of tennis elbow in a population of workers in an engineering industry.

In: Ergonomics, London, 30(1987) pp. 573-80.

Trade Union Technical Bureau:

Communication from the Commission to the European Parliament, the Council, the European Economic and Social Committee and the Committee of Regions on the Practical implementation of the Healthy and Safety at Work directives.

Brussels, COM(2004), 62 Final. 